\title{
Intracranial Subdural Hematoma after Spinal Anesthesia: Report of Two Cases with different Outcomes
}

\section{Hematoma subdural intracraniano após raquianestesia: relato de dois casos com diferentes desfechos}

\author{
Guilherme Gago $^{2}$ Otávio Garcia Martins ${ }^{10}$ Pedro Luís Gobatto ${ }^{2}$ Fernando Antônio de Oliveira Costa ${ }^{3}$ \\ Ricardo Santin ${ }^{2}$ Matheus Prado Magalhães ${ }^{2}$ Antônio Delacy Martini Vial ${ }^{2}$
}

\footnotetext{
${ }^{1}$ Department of Specialized Medicine, Universidade Federal de Pelotas, Pelotas, RS, Brazil

2 Department of Neurosurgery, Hospital São José, Santa Casa de Misericórdia de Porto Alegre, Porto Alegre, Brazil

${ }^{3}$ Department of Neurosurgery, Universidade Federal de São Paulo, São Paulo, SP, Brazil
}

\begin{abstract}
Address for correspondence Otávio Garcia Martins, Departamento de Medicina Especializada, Universidade Federal de Pelotas, Av. Duque de Caxias, 250, Pelotas, Rio Grande do Sul, Brazil, CEP 96030-000 (e-mail: otvmartins@gmail.com).
\end{abstract}

Arq Bras Neurocir 2019;38:215-218.

\section{Abstract \\ Keywords \\ - subdural hematoma \\ - spinal anesthesia \\ - intracranial bleeding \\ - anesthesia complication.}

\section{Resumo}

Palavras-chave

- hematoma subdural

- raquianestesia

- hemorragia intracraniana

- complicação anestésica
Spinal anesthesia is a technique commonly used for local anesthesia and in obstetric surgeries. Rarely, the formation of an intracranial subdural hematoma (SDH) may result from spinal anesthesia, constituting a serious condition that often leads to severe neurological deficits. The presentation and course of this pathology may occur in a completely different way, which makes its diagnosis and management difficult. In the present article, the authors report two cases of patients with intracranial SDH after spinal anesthesia with completely different presentations and outcomes, demonstrating the variability of the manifestations of this condition. A quick review of key points of its pathophysiology, symptomatology, diagnosis, and treatment was also performed.

Raquianestesia é uma técnica comumente utilizada para procedimentos locais e cirurgias obstétricas. Raramente, a formação de um hematoma subdural intracraniano pode ser resultado de uma raquianestesia, constituindo uma condição grave que frequentemente leva a déficits neurológicos severos. A apresentação e o curso desta patologia podem ocorrer de formas completamente distintas, fato que dificulta seu diagnóstico e manejo. No presente artigo, os autores relatam dois casos de pacientes que desenvolveram um hematoma subdural intracraniano após raquianestesia com apresentações e desfechos completamente diferentes, demonstrando a variabilidade das manifestações desta condição. Uma rápida revisão dos pontos-chave da fisiopatologia, da sintomatologia, do diagnóstico e do tratamento também foi realizada.

(1) Otávio Garcia Martins's ORCID is https://orcid.org/0000-00026084-0744.

received

March 18, 2019

accepted

April 17, 2019
DOI https://doi.org/

10.1055/s-0039-1692123. ISSN 0103-5355.
Copyright $(2019$ by Thieme Revinter

Publicações Ltda, Rio de Janeiro, Brazil
License terms

c) $\oplus \triangleq \$$ 


\section{Introduction}

Spinal anesthesia is a technique commonly used for local anesthesia and in obstetric surgeries. It is considered a safe procedure and has a complication rate of $\sim 0.05 \%{ }^{1,2}$ The most commonly reported complication is postdural puncture headache (PDPH), characterized by its short duration and its relation to postural changes. ${ }^{3,4}$ This complication usually has its resolution spontaneously, without further repercussion for the patient. However, more rarely, the formation of an intracranial subdural hematoma (SDH) may result from spinal anesthesia, constituting a serious condition and often leading to severe neurological deficits. ${ }^{4,5}$

The authors report two cases of intracranial SDH after spinal anesthesia that had completely different outcomes, suggesting the variability of the course of this rare complication. A review of the literature, presenting the key points of its clinical course, diagnosis, and treatment are discussed in the present article.

\section{Case Report}

\section{Case 1}

A 29-year-old female, with no previous comorbidities and no history of use of antiplatelet or anticoagulant medication, was submitted to spinal anesthesia for a cesarean delivery. The procedure had no complications and the patient was discharged in good general condition.

About 48 hours after hospital discharge, the patient sought emergency care due to a sudden onset of a left hemicranial headache of moderate intensity that was associated with nausea and vomiting, which improved in dorsal decubitus. Due to the clinical suggestion of intracranial hypotension, postspinal headache was suspected and she was recommended to rest, receiving simple analgesics and being released to go home.

However, after 72 hours, she presented back to the emergency department due to the persistence of the symptoms. Due to the unusual course of the case, a computed tomography (CT) was requested, which showed no abnormalities, and the patient was released again.

About 2 weeks later, she sought our service with worsening of the headache, this time without the postural features, associated with weakness of the right side of the body and speech disorders. The neurological physical examination demonstrated expressive dysphasia, muscle strength grade 4 in the right upper limb, and grade $4+$ in the lower right limb, according to the modified scale of the Medical Research Council (mMRC), and mild right hyperreflexia. A magnetic resonance imaging (MRI) exam of the skull was performed, demonstrating a left parietal subdural collection, with a slight mass effect characterized by deletion of the sulci and of the adjacent cortical rotations, without shifting of the midline structures (-Fig. 1). Conservative treatment with analgesics, dexamethasone, and phenytoin was indicated.

The patient progressed well, without sequelae, and was discharged 3 days later on dexamethasone and phenytoin. At

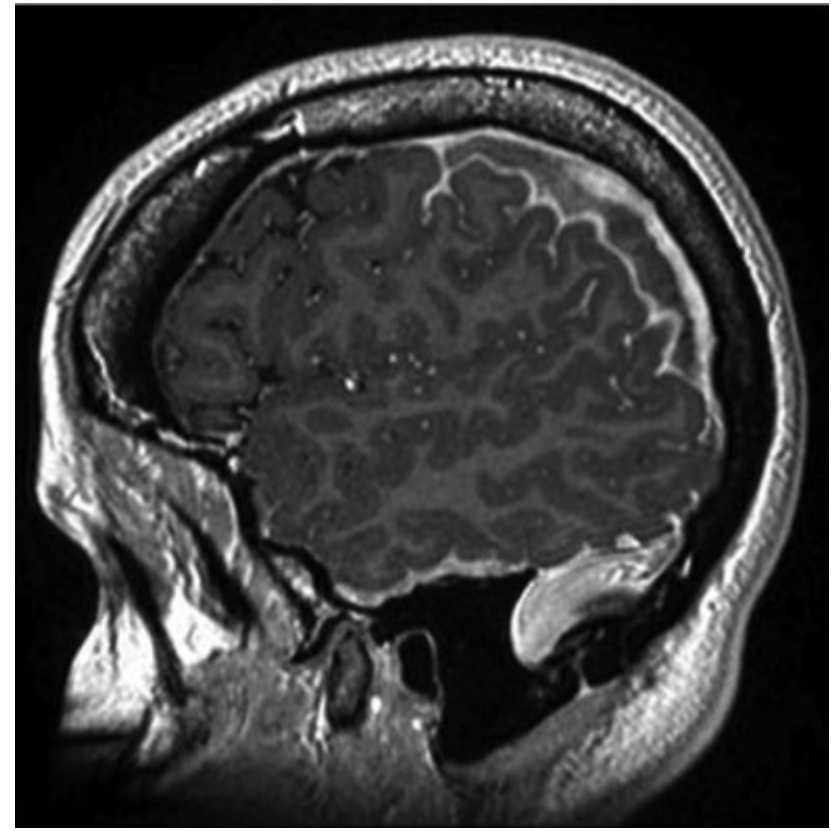

Fig. 1 Magnetic resonance imaging of the skull, T1-weighted, sagittal plane, 14 days after spinal anesthesia, demonstrating left subacute subdural hematoma.

the last follow-up, 18 months after discharge, the patient presented no symptoms. The MRI performed at the follow-up demonstrated a complete resolution of the subdural collection (-Fig. 2).

\section{Case 2}

A 37-year-old female, with no previous comorbidities and no history of use of antiplatelet or anticoagulant medication, was submitted to spinal anesthesia for a cesarean delivery. The procedure was performed without intercurrences;

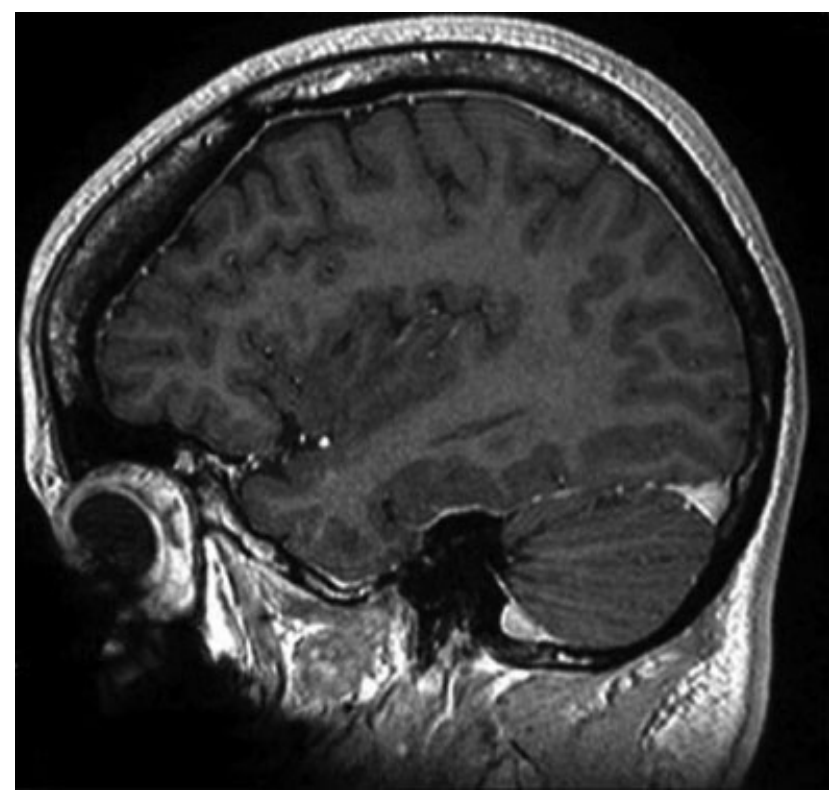

Fig. 2 Magnetic resonance imaging of the skull, T1-weighted, sagittal plane. Section evidencing complete reabsorption of the hematoma 18 months after the diagnosis. 
however, 12 hours after hospital discharge, the patient presented with a right hemicranial headache of strong intensity and vomiting associated with altered level of consciousness: mental confusion and drowsiness. The patient was submitted to a CT of the head, which demonstrated a hematoma in the subdural space in the right frontotemporal region. The collection exerted mass effect and distorted the ventricular and brainstem anatomy.

Faced with the diagnosis of an acute SDH that generated an important neurological deficit, the patient underwent surgical drainage of the clot by burr holes. The procedure was performed without intercurrences; but, in 24 hours, the patient presented worsening of the level of consciousness and anisocoria. A new CT revealed the presence of a large hemispheric edema ipsilateral to the lesion that increased the shifting of the midline structures (-Fig. 3 ).

Due to the acute scenario of neurological deterioration, the patient was submitted to emergency decompression craniectomy and was transferred to the intensive care unit (ICU) ( - Fig 4). The postoperative period was marked by slow recovery of motor and cognitive functions. After 18 days, cranioplasty was performed, which occurred without complications.

The patient was released after 1 week and remained with mild changes in cognitive functions in the follow-up.

\section{Discussion}

The most common complication of spinal anesthesia is PDPH, and its pathophysiology involves a process of cerebrospinal

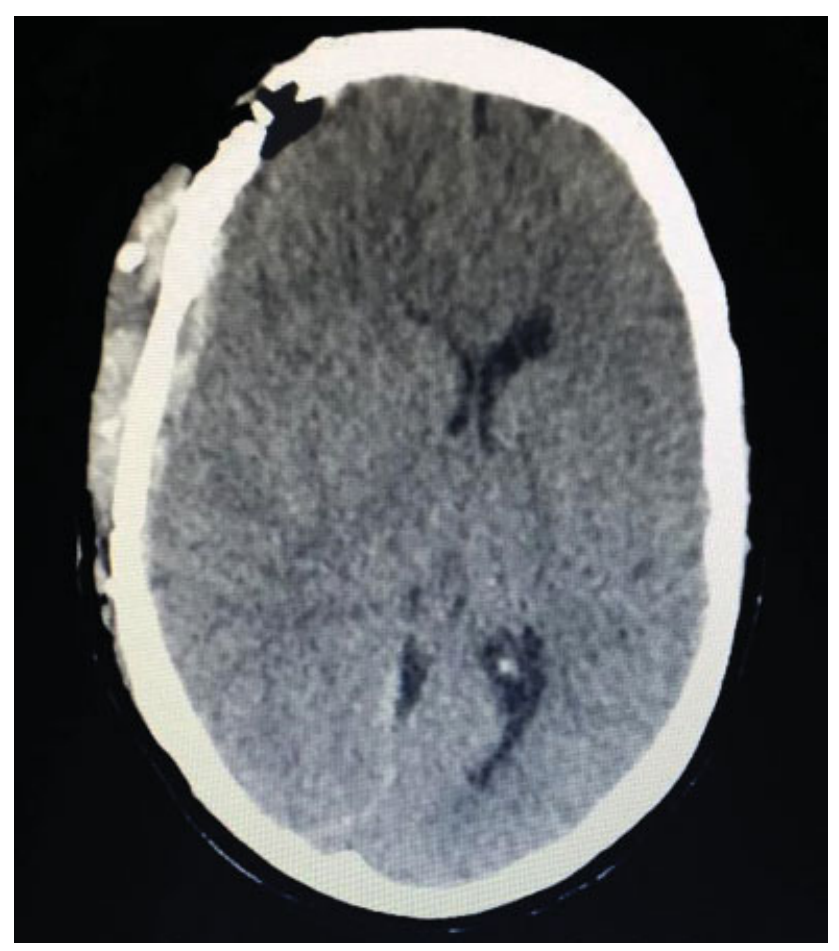

Fig. 3 Computed tomography of the skull, axial plane. Computed tomography before craniectomy. Presence of a large right hemispheric edema that increased the shifting of the midline structures and distorted the ventricular anatomy.

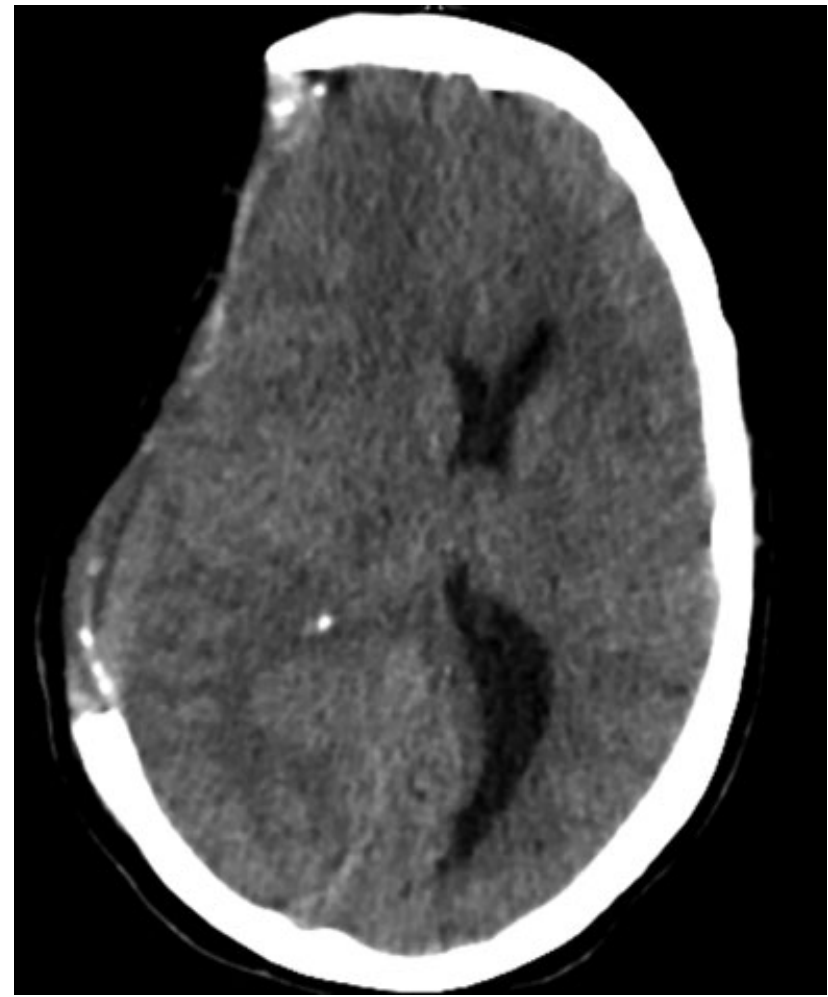

Fig. 4 Computed tomography of the skull, axial plane. Aspect of the immediate postoperative period after decompressive craniectomy, demonstrating persistent signs of shifting of the midline structures.

fluid (CSF) hypotension in the cranial subarachnoid space. This hypotension generates displacement and dural traction that depolarizes the sensitive neurons of the meninges and, hence, the algic process. ${ }^{6,7}$ Headache usually lasts for a few days and resolves spontaneously as the CSF is renewed. ${ }^{7}$

The venous drainage of the brain is made through short venous trunks called bridge veins, which pass directly from the brain to the dural sinuses, adherent to the internal plank of the skull. ${ }^{8}$ More rarely, CSF hypotension may persist and produce traction and rupture of these veins of the subdural space, leading to the formation of hematomas between the dura mater and the arachnoid space. ${ }^{6,7}$ Hypertension induced by surgical stress may be another factor that contributes to the rupture of the bridge vessels. ${ }^{4}$

Intracranial SDH may have different presentations, and often the symptoms are similar to those of PDPH, which makes the initial diagnosis difficult. According to a review of literature of 21 intracranial SDH cases after puncture of the dura mater, the earliest diagnosis occurred 2 days after the procedure, and the latest occurred after 20 weeks. $^{6}$ This variability in the timing of the diagnosis can be explained by the nonspecific symptoms that the SDH may present.

The symptoms depend on age, on the level of brain atrophy, on the size of the clot, on the topography, and on the adjacent structures involved. Thus, velocity of the clot formation and previous comorbidities of the patient may have a role in the clinical manifestations. ${ }^{4,9}$

In addition, factors related with the puncture technique (multiple attempts or inadvertent dural puncture during the 
procedure), with the size of the needle, and with the thickness of the dura seem to change the complication rates in this scenario. ${ }^{10,11}$ Finally, the use of anticoagulants in the pre- or postoperative period can lead to higher rates of complications in spinal anesthesia. ${ }^{7}$

Often, SDH can present with contralateral paresis and paresthesias, seizures, change of level of consciousness, and severe headache that are not related to orthostatism. ${ }^{7}$ Secondly, there may be intensification of headache due to intracranial hypertension syndrome, which may be associated with nausea, vomiting, papilledema, and signs of radicular irritation. 4

In suspicion of an intracranial SDH (by the presence of any of the symptoms cited above), a neuroimaging technique should be performed to identify the nature of the neurological dysfunction. Computed tomography of the head is the most widely used imaging study owing to its speed, relative simplicity, widespread availability, and good capacity to identify intracranial hematomas. Magnetic resonance imaging is also a good imaging technique for the detection of small, tentorial, and interhemispheric SDHs. ${ }^{12}$

Our first case presented with an insidious hematoma that generated important symptoms in the patient. The diagnosis was made 3 weeks after the anesthetic procedure, and conservative management was chosen. The outcome was favorable: the patient did not present neurological symptoms in the follow-up period, and control imaging evidenced complete reabsorption of the hematoma.

However, our second case had an unfavorable evolution, presenting important neurological symptoms, such as change of level of consciousness and shifting of the midline structures. Two surgical interventions were performed, including an emergency craniectomy due to quick neurological deterioration.

Our cases illustrate the difficulty of the diagnosis of intracranial SDH after spinal anesthesia due to its variability of presentations and course. The same etiologic agent may be treated nonsurgically without major complications, but may require neurointensive care due to severe structural damage to the brain.

The choice of treatment is based on the size of the hematoma and on the patient's clinic. Small clots, which cause few symptoms that do not course with shifting of the midline structures in neuroimaging, can be monitored conservatively and do not require surgery. In a review of 35 cases of intracranial SDH following spinal anesthesia, 27 patients (77\%) required surgical intervention, 4 (11\%) developed neurologic deficits, and $4(11 \%)$ died. ${ }^{4}$ The present review showed that this type of complication may have a broad spectrum of possible outcomes, which are difficult to predict in its early stages.

\section{Conclusion}

Due to the potential lethality of this condition, intracranial SDH after spinal anesthesia should be identified and treated as early as possible. Situations that can alert the physician to suspect this condition include: postural headache for $>1$ week or changes in this pain to nonpostural headache, or the development of other neurologic signs or symptoms besides the headache. In this scenario, a CT or an MRI are mandatory for a proper evaluation of this disease.

\section{Conflicts of Interests}

The authors have no conflicts of interests to declare.

\section{References}

1 Aromaa U, Lahdensuu M, Cozanitis DA. Severe complications associated with epidural and spinal anaesthesias in Finland 1987-1993. A study based on patient insurance claims [see comment]. Acta Anaesthesiol Scand 1997;41(04):445-452. Doi: 10.1111/j.1399-6576.1997.tb04722.x

2 Auroy Y, Narchi P, Messiah A, Litt L, Rouvier B, Samii K. Serious complications related to regional anesthesia: results of a prospective survey in France. Anesthesiology 1997;87(03):479-486. DOI: 10.1097/00000542-199709000-00005

3 Lybecker H, Djernes M, Schmidt JF. Postdural puncture headache (PDPH): onset, duration, severity, and associated symptoms. An analysis of 75 consecutive patients with PDPH. Acta Anaesthesiol Scand 1995;39(05):605-612. DOI: 10.1111/j.1399-6576.1995. tb04135.x

4 Amorim JA, Remígio Ddos A, Damázio Filho O, de Barros MA, Carvalho VN, Valença MM. Intracranial subdural hematoma postspinal anesthesia: report of two cases and review of 33 cases in the literature. Rev Bras Anestesiol 2010;60(06):620-629, 344349. DOI: 10.1016/S0034-7094(10)70077-5

5 Ramos-Aparici R, Segura-Pastor D, Edo-Cebollada L, Vila-Sánchez M. Acute subdural hematoma after spinal anesthesia in an obstetric patient. J Clin Anesth 2008;20(05):376-378. DOI: 10.1016/j. jclinane.2008.01.010

6 Zeidan A, Farhat O, Maaliki H, Baraka A. Does postdural puncture headache left untreated lead to subdural hematoma? Case report and review of the literature. Middle East J Anaesthesiol 2010;20 (04):483-492. DOI: 10.1016/j.ijoa.2005.07.001

7 Bisinotto FMB, Dezena RA, Fabri DC, Abud TMV, Canno LH. Hematoma Subdural Intracraniano: Uma Rara Complicação após Raquianestesia: Relato de Caso. Rev Bras Anestesiol 2012; 62(01):88-95. DOI: 10.1016/S0034-7094(12)70107-1

8 Han H, Tao W, Zhang M. The dural entrance of cerebral bridging veins into the superior sagittal sinus: an anatomical comparison between cadavers and digital subtraction angiography. Neuroradiology 2007;49(02):169-175. DOI: 10.1007/s00234006-0175-Z

9 Mellergård P, Wisten O. Operations and re-operations for chronic subdural haematomas during a 25-year period in a well defined population. Acta Neurochir (Wien) 1996;138(06):708-713

10 Khraise WN, Allouh MZ, El-Radaideh KM, Said RS, Al-Rusan AM. Assessment of risk factors for postdural puncture headache in women undergoing cesarean delivery in Jordan: a retrospective analytical study. Local Reg Anesth 2017;10:9-13. DOI: 10.2147/ LRA.S129811

11 Valença M, Amorim J, Barros M. Risk factors for postdural puncture headache: experience with spinal anesthesia. Cephalalgia 2007;27:716-717

12 Gentry LR, Godersky JC, Thompson B, Dunn VD. Prospective comparative study of intermediate-field MR and CT in the evaluation of closed head trauma. AJR Am J Roentgenol 1988;150(03): $673-682$ 